\title{
Retraction Note: Urban vegetation coverage based on multi-core learning characteristics and regional economic law planning
}

\section{Daochun Wang ${ }^{1,2}$}

Published online: 17 November 2021

C) Saudi Society for Geosciences 2021

Retraction Note: Arabian Journal of Geosciences (2021) 14: 1638 https://doi.org/10.1007/s12517-021-07941-3

The Editor-in-Chief and the Publisher have retracted this article because the content of this article is nonsensical. The peer review process was not carried out in accordance with the Publisher's peer review policy. The author has not responded to correspondence regarding this retraction.

The original article can be found online at https://doi.org/10.1007/ s12517-021-07941-3.

Daochun Wang

wdcwdc138@163.com

1 School of Law Hunan University, Changsha 410012, Hunan,

China

2 Hunan Police Academy, Changsha 410138, Hunan, China 